\title{
Improvement of OMI ozone profile retrievals by simultaneously fitting polar mesospheric clouds
}

\author{
Juseon Bak ${ }^{1}$, Xiong Liu ${ }^{2}$, Jae H. Kim ${ }^{1}$, Matthew T. Deland ${ }^{3}$, and Kelly Chance ${ }^{2}$ \\ ${ }^{1}$ Pusan National University, Department of Atmospheric Sciences, Busan, South Korea \\ ${ }^{2}$ Harvard-Smithsonian Center for Astrophysics, Cambridge, MA, USA \\ ${ }^{3}$ Systems and Applications, Inc. (SSAI), 10210 Greenbelt Rd., Suite 600, Lanham, MD 20706, USA \\ Correspondence to: Jae H. Kim (jaekim@pusan.ac.kr)
}

Received: 29 March 2016 - Published in Atmos. Meas. Tech. Discuss.: 4 April 2016

Revised: 18 August 2016 - Accepted: 19 August 2016 - Published: 13 September 2016

\begin{abstract}
The presence of polar mesospheric clouds (PMCs) at summer high latitudes could affect the retrieval of ozone profiles using backscattered ultraviolet (UV) measurements. PMC-induced errors in ozone profile retrievals from Ozone Monitoring Instrument (OMI) backscattered UV measurements are investigated through comparisons with Microwave Limb Sounder (MLS) ozone measurements. This comparison demonstrates that the presence of PMCs leads to systematic biases for pressures smaller than $6 \mathrm{hPa}$; the biases increase from $\sim-2 \%$ at $2 \mathrm{hPa}$ to $\sim-20 \%$ at $0.5 \mathrm{hPa}$ on average and are significantly correlated with brightness of PMCs. Sensitivity studies show that the radiance sensitivity to PMCs strongly depends on wavelength, increasing by a factor of $\sim 4$ from 300 to $265 \mathrm{~nm}$. It also strongly depends on the PMC scattering, thus depending on viewing geometry. The optimal estimation-based retrieval sensitivity analysis shows that PMCs located at 80-85 km have the greatest effect on ozone retrievals at $\sim 0.2 \mathrm{hPa}(\sim 60 \mathrm{~km})$, where the retrieval errors range from $-2.5 \%$ with PMC vertical optical depth (POD) of $10^{-4}$ to $-20 \%$ with $10^{-3}$ POD at backscattering angles. The impacts increase by a factor of $\sim 5$ at forward-scattering angles due to stronger PMC sensitivities. To reduce the interference of PMCs on ozone retrievals, we perform simultaneous retrievals of POD and ozone with a loose constraint of $10^{-3}$ for POD, which results in retrieval errors of $1-4 \times 10^{-4}$. It is demonstrated that the negative bias of OMI ozone retrievals relative to MLS can be improved by including the $\mathrm{PMC}$ in the forward-model calculation and retrieval.
\end{abstract}

\section{Introduction}

Polar mesospheric clouds (PMCs) are tenuous layers of ice crystals that form at $80-85 \mathrm{~km}$ altitude only during the hemispheric summer season $(\sim 30$ days before to $\sim 65$ days after summer solstice) at high latitudes and occasionally at midlatitudes (Thomas et al., 1991; Taylor et al., 2002; DeLand et al., 2010). It has been suggested that the change of PMC properties such as frequency and brightness is linked to longterm changes in the composition and thermal structure of our atmosphere caused by human activities.

Mesospheric clouds in the daytime are detectable only from space, whereas ground-based observations are limited to immediately after sunset or before sunrise (DeLand et al., 2006). The optimal way to observe PMCs from space is to employ limb-viewing sensors measuring scattered solar radiation, from which the cloud layers are easily identified as enhanced radiances against the relatively weak atmospheric scattering (Thomas et al., 1991; Deland et al., 2006). The seasonal-latitudinal behaviors of PMC occurrence, brightness, and altitude were characterized from various limb-viewing instruments including the Solar Mesosphere Explorer (SME), the Student Nitric Oxide Explorer (SNOE), the SCanning Imagining Absorption spectroMeter for Atmospheric CHartographY (SCIAMACHY), and the Solar Occultation For Ice Experiment (SOFIE) (Olivero and Thomas, 1986; Bailey et al., 2005; von Savigny et al., 2004; Hervig and Stevens, 2014). These satellite measurements contributed to understanding of microphysical properties of PMCs such as ice water content, size distribution, and shape, although they still remain a challenge (e.g., Thomas, 1984; 
Rapp et al., 2007; von Savigny and Burrows, 2007, Hervig et al., 2009).

Even though nadir-viewing sensors could not provide information about the PMC altitude, Thomas et al. (1991) first demonstrated that PMCs are detectable from nadir-looking UV measurements using a brightness-based detection algorithm. PMC occurrence and brightness have been derived from Solar Backscatter UltraViolet (SBUV, SBUV/2), Ozone Monitoring Instrument (OMI), and Cloud Imaging and Particle Size (CIPS) nadir UV measurements at wavelengths below $300 \mathrm{~nm}$, where the Rayleigh-scattered background is comparatively low due to very strong ozone absorption. Thomas et al. (1991) found an anti-correlation of the PMC occurrence frequency with solar activity from 8 years of SBUV albedo data over the period 1978-1986. Further studies have demonstrated long-term trends over $30+$ years in PMC occurrence frequency, brightness, particle radii, and ice water content (DeLand et al., 2003, 2007; Shettle et al., 2009; Hervig and Stevens, 2014; DeLand and Thomas, 2015). OMI PMC observations were used to characterize the local time variation of PMC occurrence frequency and brightness, with the advantage of overlapping pixels over the polar region due to the wide swath of OMI (DeLand et al., 2011). CIPS on board the Aeronomy of Ice in the Mesosphere (AIM) images the polar atmosphere at a variety of scattering angles and thus provides a direct measurement of the cloud scattering phase function from which the size distribution, index of refraction, and shape of the ice particles could be derived (Bailey et al., 2009). On the other hand, the detectability of PMCs from UV wavelengths below $300 \mathrm{~nm}$ implies that failure to account for PMCs in ozone profile retrievals using these wavelengths might affect the determination of ozone and its trends in the upper atmosphere from nadir-viewing UV instruments such as SBUV, SBUV/2, OMI, Global Ozone Monitoring Experiment (GOME) (European Space Agency, 1995), SCIAMACHY (Bovensmann et al., 1999), GOME-2 (Munro et al., 2006), and Ozone Mapping and Profiler Suite (OMPS) nadir profiler instruments (Flynn et al., 2014). However, the impact of PMCs on ozone retrievals has not been taken into account for any ozone algorithm or even thoroughly investigated with sufficient statistical data.

This paper is motivated by two main goals. The first objective is to quantify the effect of PMCs on the current ozone profile retrievals from OMI measurements. For this purpose, we combine the OMI ozone profile retrieval algorithm of Liu et al. (2010a) and the OMI PMC detection product of DeLand et al. (2010) and evaluate OMI ozone profile retrievals for PMC and non-PMC pixels through comparison with collocated MLS measurements. The second objective is to simultaneously retrieve the PMC vertical optical depth (POD) with ozone using an optimal estimation technique, to reduce the interference on ozone profile retrievals.

In Sect. 2 we briefly introduce satellite measurements of OMI and MLS used in this study and then describe the PMC detection product and the POD retrieval algorithm, respec- tively. In Sect. 3.1 we evaluate OMI ozone profile retrievals (without POD retrievals) against MLS ozone profiles during the PMC season. Section 3.2 presents the results from a retrieval sensitivity study to see if OMI measurements provide adequate sensitivity to measure PODs. The improvement of ozone profile retrievals with simultaneously retrieved POD is discussed in Sect. 3.3. We summarize and conclude our results in Sect. 4.

\section{Data and methods}

\subsection{OMI and MLS ozone measurements}

Both the OMI and MLS instruments are on board the NASA Earth Observing System (EOS) Aura satellite, which is flown in a $705 \mathrm{~km}$ sun-synchronous polar orbit with an Equatorcrossing time at $\sim 13: 45$ (Schoeberl et al., 2006). MLS measurements are taken about $7 \mathrm{~min}$ ahead of OMI at the same locations during daytime orbital tracks.

OMI is a nadir-viewing, ultraviolet-visible imaging spectrometer that measures backscattered radiances from 260 to $500 \mathrm{~nm}$ (UV-1: 260-310 nm; UV-2: 310-365 nm; VIS: 365$500 \mathrm{~nm}$ ) at spectral resolutions of $0.42-0.63 \mathrm{~nm}$ with daily global coverage (Levelt et al., 2006). The spatial resolution is $13 \times 24 \mathrm{~km}^{2}$ for UV-2 and VIS and $13 \times 48 \mathrm{~km}^{2}$ for UV-1 at nadir position in the global mode. The OMI science teams provide two operational total ozone products, OMTO3 (Bhartia and Wellemeyer, 2002) and OMDOAO3 (Veefkind et al., 2006), and one operational ozone profile product, OMO3PR (Kroon et al., 2011). We use the Smithsonian Astrophysical Observatory (SAO) ozone profile algorithm (Liu et al., 2010a) to deal with the error analysis of ozone profile retrievals due to PMC contamination. This algorithm retrieves partial column ozone at 24 layers (surface to $\sim 65 \mathrm{~km}$ ) from OMI measurements with the fitting window of 270-330 nm, based on the well-known optimal estimation (OE) technique (Rodgers, 2000). The iterative solution of the nonlinear problem is given as

$$
\begin{aligned}
\boldsymbol{X}_{i+1}= & \boldsymbol{X}_{i}+\left(\mathbf{K}_{i}^{\mathrm{T}} \mathbf{S}_{y}^{-1} \mathbf{K}_{i}+\mathbf{S}_{\mathrm{a}}^{-1}\right)^{-1} \\
& {\left[\mathbf{K}_{i}^{\mathrm{T}} \mathbf{S}_{y}^{-1}\left(\boldsymbol{Y}-R\left(\boldsymbol{X}_{i}\right)\right)-\mathbf{S}_{\mathrm{a}}^{-1}\left(\boldsymbol{X}_{i}-\boldsymbol{X}_{\mathrm{a}}\right)\right], }
\end{aligned}
$$

where $\boldsymbol{X}_{i+1}, \boldsymbol{X}_{i}, \boldsymbol{X}_{\mathrm{a}}$, and $\boldsymbol{Y}$ are the current and previous state vectors, a priori vector, and measured radiance vector (defined as logarithm of normalized radiance), respectively. In order to improve fitting residuals, non-ozone parameters are also in the state vector, including $\mathrm{BrO}$, surface albedo, wavelength shifts between radiance and irradiance and between radiance and ozone cross sections, and scaling parameters for the Ring effect and mean fitting residuals. $R\left(\boldsymbol{X}_{i}\right)$ and $\mathbf{K}_{i}$ are the simulated logarithms of radiance spectrum and the weighting function matrix $\left(\partial R / \partial X_{i}\right)$ calculated using the Vector LInearized Discrete Ordinate Radiative Transfer model (VLIDORT) (Spurr, 2006, 2008). The measurement error covariance matrix and a priori error covariance 
matrix are defined as $\mathbf{S}_{y}$ and $\mathbf{S}_{\mathrm{a}}$, respectively. Ozone a priori information is generally taken from climatological mean values and standard deviations of long-term measurement data. This iterative process is performed until the cost function $\chi^{2}$ (Eq. 2) converges:

$$
\begin{aligned}
\chi^{2} & =\left\|\mathbf{S}_{y}^{-\frac{1}{2}}\left\{\mathbf{K}_{i}\left(\boldsymbol{X}_{i+1}-\boldsymbol{X}_{i}\right)-\left[\boldsymbol{Y}-R\left(\boldsymbol{X}_{i}\right)\right]\right\}\right\|_{2}^{2} \\
& +\left\|\mathbf{S}_{\mathrm{a}}^{-\frac{1}{2}}\left(\boldsymbol{X}_{i+1}-\boldsymbol{X}_{\mathrm{a}}\right)\right\|_{2}^{2},
\end{aligned}
$$

where \|\|$_{2}^{2}$ denote the sum of each element squared.

The quality of the retrievals can be characterized by the solution error, defined as the root square sum of the random noise error and smoothing error. The vertical resolution estimated by Liu et al. (2010a) is $\sim 7-11 \mathrm{~km}$ in the stratosphere. The retrieval random noise errors range from $1 \%$ in the middle stratosphere to $10 \%$ in the lower stratosphere, and the solution errors are typically $1-6 \%$ in the stratosphere

MLS is a forward-looking, thermal-emission, microwave limb sounder that takes measurements along track and performs 240 limb scans per orbit with a footprint of $\sim 6 \mathrm{~km}$ across track and $\sim 200 \mathrm{~km}$ along track (Waters et al., 2006). The MLS ozone used here is the version 4.2 standard ozone product (55 pressure levels) retrieved from the $240 \mathrm{GHz}$ radiance information, publicly available from the NASA Goddard Earth Sciences Data and Information Services Center (GES DISC). The typical vertical resolution of this product is $2.5-3.5 \mathrm{~km}$ from 261 to $0.2 \mathrm{hPa}$ and $4.0-5.5 \mathrm{~km}$ from 0.1 to $0.02 \mathrm{hPa}$; the precision is estimated to be a few percent in the middle stratosphere, but $5-100 \%$ below $150 \mathrm{hPa}$ and 60 $300 \%$ above $0.1 \mathrm{hPa}$. We apply all the data-screening criteria recommended in Livesey et al. (2015) and hence limit MLS ozone data to "quality" higher than 1.0, "convergence" lower than 1.03 , and positive "precision" values and even "status" value for the pressure range of $261-0.02 \mathrm{hPa}$.

Liu et al. (2010b) used the v2.2 MLS ozone data to validate the OMI ozone profile retrievals and demonstrated the excellent OMI-MLS agreement of within $4 \%$ in the middle stratosphere, except for positive biases of $5-10 \%$ above $0.5 \mathrm{hPa}$ and negative biases of $10-15 \%$ below $100 \mathrm{hPa}$, which are greatly improved by accounting for OMI's coarser vertical resolution using OMI averaging kernels.

\subsection{OMI PMC product}

The flag data to detect both PMC and non-PMC regions from OMI measurements are provided by DeLand et al. (2010). This detection algorithm uses albedo data $(A=I / F$, where $I$ is radiance and $F$ is irradiance) at $267,275,283.5,287.5$, and $292.5 \mathrm{~nm}$ after interpolating all spectra to a $0.5 \mathrm{~nm}$ grid and averaging three consecutive bins. The PMC pixels are identified using enhancements above the Rayleigh scattering background. The background atmospheric albedo due to Rayleigh scattering and ozone absorption $\left(A_{\text {ray }}\right)$ is deter-

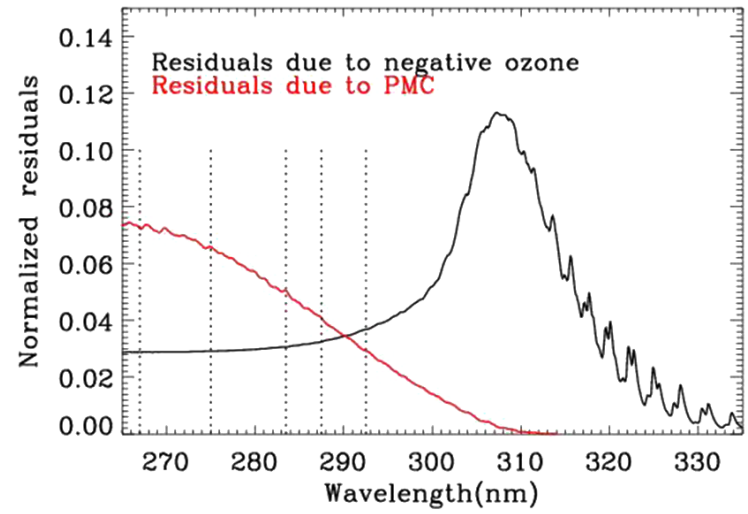

Figure 1. Radiance residuals due to the subtraction of $5 \%$ of background ozone at each layer (black line) and due to PMC scattering with POD of $10^{-3}$ (red line), normalized to background radiance. The vertical dashed lines represent five wavelengths used in OMI PMC detection.

mined using a fourth-order fit in solar zenith angle to nonPMC pixels for each orbit, after applying a geometric adjustment for cross-track albedo variations as defined in Eq. (4) of DeLand et al. (2010). Positive signals of albedo residuals $\left(A-A_{\text {ray }}\right)$ could be induced by "false PMCs", including random instrument noise and geophysical variability of ozone, as well as by the PMC scattering. The minimum residual albedo value for PMC detection is derived from the variability of out-of-PMC season measurements, as described in Sect. 3 of DeLand et al. (2010). The derived threshold function varies from approximately $6.5 \times 10^{-6} \mathrm{sr}^{-1}$ at $40^{\circ}$ latitude to $4.7 \times 10^{-6} \mathrm{sr}^{-1}$ at $81^{\circ}$ latitude (see Fig. 3 of DeLand et al., 2010) and is scaled up by an empirical factor of 1.6 to eliminate false PMC detections at the start and end of the PMC season. The false PMC signals due to a negative ozone deviation are screened out using the wavelength dependence of PMC signals that become stronger at shorter wavelengths, whereas the residuals due to a negative ozone deviation increase at longer wavelengths for PMC detection wavelengths, as shown in Fig. 1. The criteria for identifying PMC signals using residual albedo values are described in DeLand et al. (2003) and DeLand et al. (2007). PMCs are typically observed at latitudes above $55^{\circ}$ from OMI where solar zenith angles (SZAs) are above $\sim 35^{\circ}$, viewing zenith angles (VZAs) are below $\sim 70^{\circ}$, relative azimuth angles (AZAs) range from $\sim 40$ to $\sim 80^{\circ}$ (east side of the nadir swath) and from $\sim 110$ and $\sim 130^{\circ}$ (west side of the nadir swath), and the scattering angles vary between 60 and $160^{\circ}$

\subsection{PMC optical depth retrievals}

In the standard ozone retrieval mode, the atmosphere is divided into 24 layers; the bottom level of a layer $i$ is defined as $P_{i}=2^{-\frac{(i-1)}{2}} \times 1013.15 \mathrm{hPa}$, with the top of atmosphere, 
the upper level of layer 24 , set at $0.087 \mathrm{hPa}(\sim 65 \mathrm{~km})$. Radiance calculations are made using the VLIDORT model for a Rayleigh atmosphere (no aerosol) assuming Lambertian reflectance for ground surface and for clouds.

In the POD retrieval mode, we add five more layers between $\sim 65$ and $\sim 90 \mathrm{~km}$ at $5 \mathrm{~km}$ intervals; the bottom level of a layer $i$ is defined as $P_{i}=10^{-\left(\frac{(i-25) \times 5+65}{16}\right)} \times 1013.15 \mathrm{hPa}$ for $i=25, \ldots, 29$. PMC particles are inserted into the single layer from 80 to $85 \mathrm{~km}$. Simulating the scattering particles in the radiative process requires the specification of a particle size distribution, the distribution size, the distribution dispersion width, and a particle shape. The primary component of PMC particles was first confirmed as nonspherical ice crystals by Hervig et al. (2001). The range of reported radii and size distribution widths is $15-100$ and 10$20 \mathrm{~nm}$, respectively, and lognormal or Gaussian size distributions are normally assumed (Englert et al., 2007; Hervig et al., 2009). Here we assumed PMCs to be spherical ice particles with a lognormal size distribution $\left(r_{\mathrm{o}}=55 \mathrm{~nm}, \sigma_{\mathrm{g}}=\right.$ 1.4) because the particle shape plays a minor role in the UV scattering (Baumgarten and Thomas, 2005; Eremenko et al., 2005), so we can derive extinction, single-scattering albedo, and phase function as a function of wavelength from Mie theory. The ice refractive index, $1.33+5 \times 10^{-9} i$ at $300 \mathrm{~nm}$ from Warren (1984), was used for the entire wavelength range because of low dependence on UV wavelength. The temperature profile is taken from daily National Centers for Environmental Prediction (NCEP) final (FNL) operational global analysis data (http://rda.ucar.edu/datasets/ ds083.2/) below $10 \mathrm{hPa}$, European Centre for Medium-Range Weather Forecasts (ECMWF) temperature profile climatology between 7 and $1 \mathrm{hPa}$ (http://ecmwf.int/), and Total Ozone Mapping Spectrometer (TOMS) V8 temperature climatology above (Bhartia and Wellemeyer, 2002). We take ozone a priori information from monthly and zonal mean ozone profile climatology presented in McPeters and Labow (2012), which is based on the Aura MLS v3.3 data (2004-2010) and ozonesonde data (1988-2010). Climatological a priori information for PMC optical thickness is not available. It is selected here by trial and error. As a result, the a priori state and its error are set to be 0 and $10^{-3}$, respectively. The initial POD value is taken to be $10^{-4}$.

\section{Results and discussion}

\subsection{OMI-MLS comparison for with and without PODs}

The ozone profile comparisons between OMI without retrieving PODs and MLS are performed for two polar summer seasons, July 2007 for the Northern Hemisphere (NH) and January 2008 for the Southern Hemisphere (SH), when the PMC occurrence is most frequent in a given year. The comparison is limited to the high-latitude regions $75-85^{\circ} \mathrm{N}$ and $75-85^{\circ} \mathrm{S}$. The vertical range is limited to pressures larger

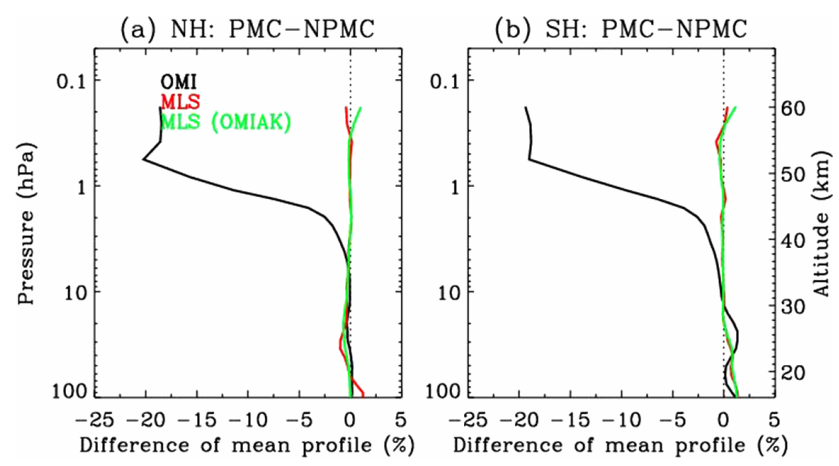

Figure 2. Difference in mean ozone profiles of OMI (black), MLS(red), and MLS convolved with OMI averaging kernels (green) between PMC and non-PMC pixels as functions of MLS vertical layers, for (a) NH 2007 (July 2007, 75-85 ${ }^{\circ}$ N) and (b) SH 2008 (January $2008,75-85^{\circ} \mathrm{S}$ ) summer seasons.

than $0.1 \mathrm{hPa}$ due to the weak vertical ozone information from OMI measurements above; the retrieval could be adequately resolved below $\sim 0.5 \mathrm{hPa}$ in the stratosphere based on the averaging kernels (not shown here). In addition, MLS data have much larger uncertainties for ozone retrievals for pressures smaller than $0.1 \mathrm{hPa}$, as mentioned in Sect. 2.1. The collocated OMI and MLS measurements are separated into PMC and non-PMC pixels using the OMI PMC detection flag specified in Sect. 2.2. OMI ozone profiles are interpolated into MLS vertical grids for comparison. In order to reduce the effect of the OMI smoothing errors on the comparison, the high-resolution MLS data are convolved with the OMI averaging kernels. Figure 2 compares the OMI and MLS ozone profiles averaged over PMC and non-PMC regions, respectively, on MLS pressure grids. Both original and smoothed MLS profiles show insignificant differences due to the presence of PMCs, but the differences become significant for the mean OMI profiles in the upper stratosphere. This demonstrates that the MLS stratospheric ozone product could be a proper reference for the evaluation of OMI ozone retrievals during a PMC season. Despite the large relative biases $(\sim-20 \%$ at $0.5 \mathrm{hPa})$ due to the presence of PMCs, the absolute bias is very small $(\sim-0.05 \mathrm{DU}$ at $0.5 \mathrm{hPa})$ because the ozone values in upper layers are quite small: the effect of PMCs on total ozone retrievals is negligible.

Figure 3 shows the mean biases and $1 \sigma$ standard deviations of relative differences between OMI and smoothed MLS ozone profiles. With non-PMC pixels, the maximum negative bias of OMI relative to MLS reaches $-12 \%$ for the $\mathrm{NH}$ and $-5 \%$ for the $\mathrm{SH}$ at $\sim 0.5 \mathrm{hPa}$. This bias increases to $-29 \%$ for the $\mathrm{NH}$ and $-22 \%$ for the $\mathrm{SH}$ when there are PMCs. The mean bias difference between PMC and non-PMC is the difference between the black and green lines in Fig. 2, almost the same as the black line since the MLS PMC-non-PMC difference is almost zero. We can see that the PMC effect on OMI retrievals starts at $\sim 6 \mathrm{hPa}$ 
(a) $\mathrm{NH}$ : OMI-MLS
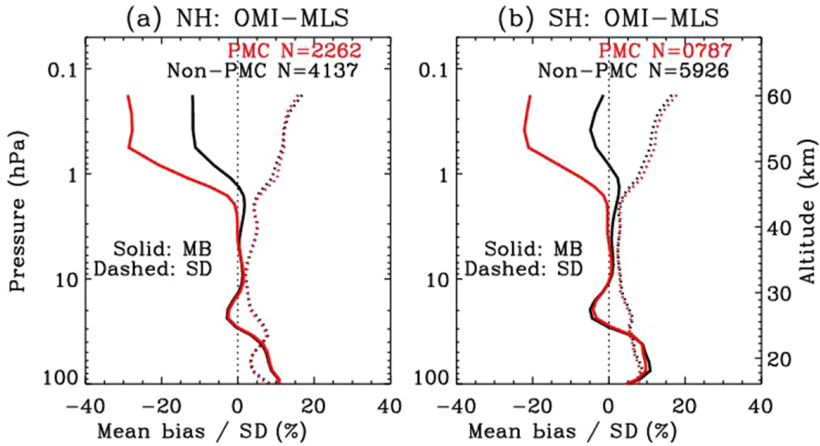

Figure 3. Same as Fig. 2 but for mean biases (solid line) and $1 \sigma$ standard deviations (dashed line) of relative differences between OMI and collocated MLS convolved with OMI averaging kernels, (OMI - MLS) / OMI a priori $\times 100 \%$ for PMC (red) and non-PMC (black) pixels. The number of collocations $(N)$ is shown in the legend.

( $\sim 35 \mathrm{~km}$ ), leading to erroneous ozone reductions of $\sim 20 \%$ at $0.5 \mathrm{hPa}$ and $\sim 2 \%$ at $2 \mathrm{hPa}$, similarly for both hemispheres. If we account for the occurrence frequency of PMCs, the overall PMC effect on average ozone at $0.5 \mathrm{hPa}$ is $7.1 \%$ $(20 \% \times 2262 / 6399)$ in the $\mathrm{NH}$ as there are $2262 \mathrm{PMC}$ pixels among 6399 pixels. This overall effect is 3 times larger compared to $2.3 \%(20 \% \times 787 / 6713)$ in the $\mathrm{SH}$.

These PMC-induced ozone errors for OMI are more significant compared to $\sim 10 \%$ PMC-induced error in individual SBUV ozone retrievals based on the SBUV version 5 algorithm (Thomas et al., 1991) and mean PMC-induced errors of up to 2-3\% in SBUV/2 ozone retrievals based on the SBUV version 8.6 algorithm (Bhartia et al, 2013). This is mainly because the spatial resolution of OMI, $48 \times 13 \mathrm{~km}$, is much smaller than SBUV $(200 \times 200 \mathrm{~km})$ and SBUV $/ 2$ $(170 \times 170 \mathrm{~km})$, so OMI has more chance to see a brighter PMC, resulting in a larger impact on ozone retrievals. In addition, the comparison of standard deviations shows almost no difference, indicating that the presence of PMCs mainly causes systematic retrieval biases.

In Fig. 4, OMI/MLS biases are plotted as functions of the PMC albedo residuals at $267 \mathrm{~nm}$ for the NH polar summer. This figure emphasizes that brighter PMCs have greater impact on the upper-atmospheric ozone retrievals from UV measurements. The OMI-MLS differences increase up to 60$80 \%$ at the topmost three layers when PMCs are very bright. For dark PMC pixels, OMI retrievals agree well with MLS (mean biases are close to 0 ), except for negative biases of $-20 \%$ at $0.15-0.46 \mathrm{hPa}$ and $-10 \%$ at $0.68-1.0 \mathrm{hPa}$. Observations from the CIPS instrument on the AIM satellite show that faint PMCs below the OMI detection threshold, with brightness as low as $1.0 \times 10^{-6} \mathrm{sr}^{-1}$, are observed in 80-90\% of all samples at $80^{\circ}$ latitude (Lumpe et al., 2013). Thus, even pixels that are "dark" based on the OMI detection threshold may still have enough PMC contamination to bias OMI ozone retrievals above $1.0 \mathrm{hPa}$. A strong negative correlation
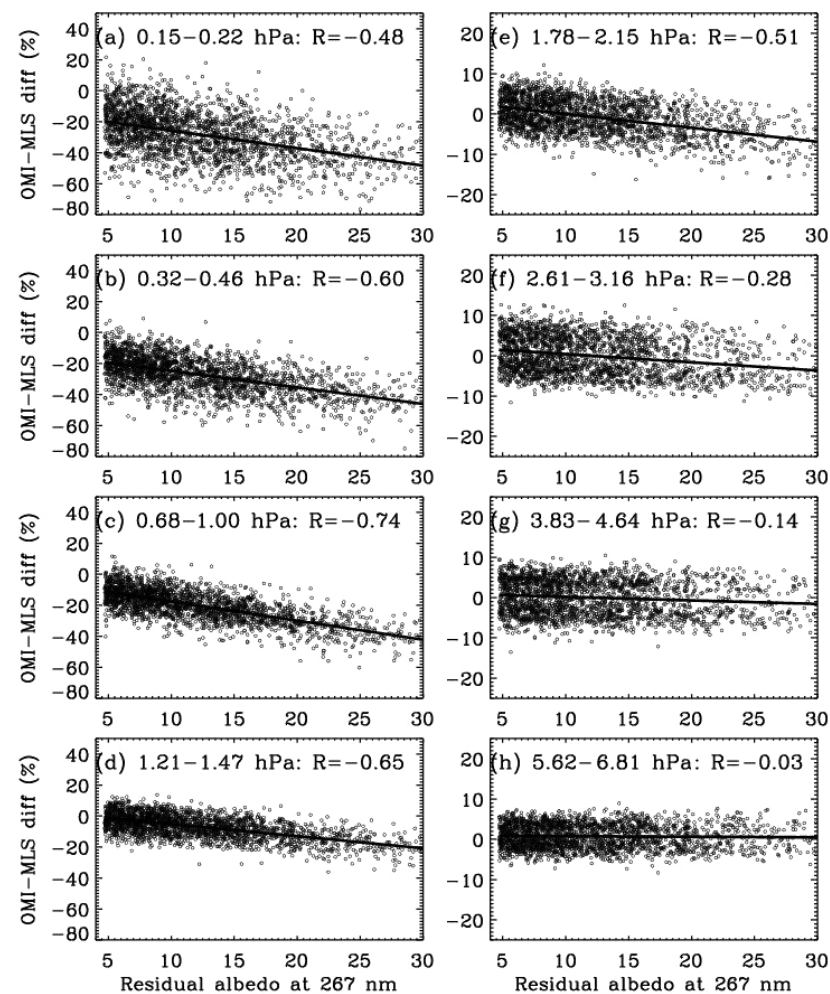

Figure 4. Scatterplots of OMI-convolved MLS partial column ozone difference (\%) for eight MLS layers and PMC albedo residual at $267 \mathrm{~nm}\left(\times 10^{-6} \mathrm{sr}^{-1}\right)$ for NH 2007 summer, with the linear regression line. The correlation coefficients $(R)$ are shown in the legend.

of more than 0.5 is found in partial ozone columns above $2 \mathrm{hPa}$, and no correlation $(<0.1)$ is found at those layers below $6 \mathrm{hPa}$. This similar behavior is detected for the relationship between biases due to PMCs and albedo residuals in the SH polar summer presented in Table 1.

\subsection{Sensitivity of UV radiances to PMCs}

In Fig. 5a, the sensitivity of OMI radiance to PODs ranging from $10^{-5}$ to $10^{-3}$ is plotted as functions of wavelength for a SZA of $70^{\circ}, \mathrm{VZA}$ of $45^{\circ}$, and AZA of $135^{\circ}$. Despite being optically thin, PMCs can significantly affect the UV radiances at shorter wavelengths where the signal is weak, implying that the effect of PMC scattering may be non-negligible for the stratospheric ozone retrievals from OMI as well as the SBUV, SBUV/2, GOME, GOME-2, SCIAMACHY, and OMPS nadir profiler instruments. The presence of PMCs with the optical depth of $10^{-3}$ enhances the radiances from $2 \%$ at $300 \mathrm{~nm}$ to $8 \%$ at $265 \mathrm{~nm}$ for AZA of $135^{\circ}$. This sensitivity increases 4 times for the same SZA and VZA but for AZA of $45^{\circ}$ (Fig. 5b). Furthermore, it is shown that POD should be larger than $\sim 10^{-4}$ for the case in Fig. 5a and larger than $\sim 2 \times 10^{-5}$ in Fig. $5 \mathrm{~b}$ to be detectable from UV mea- 

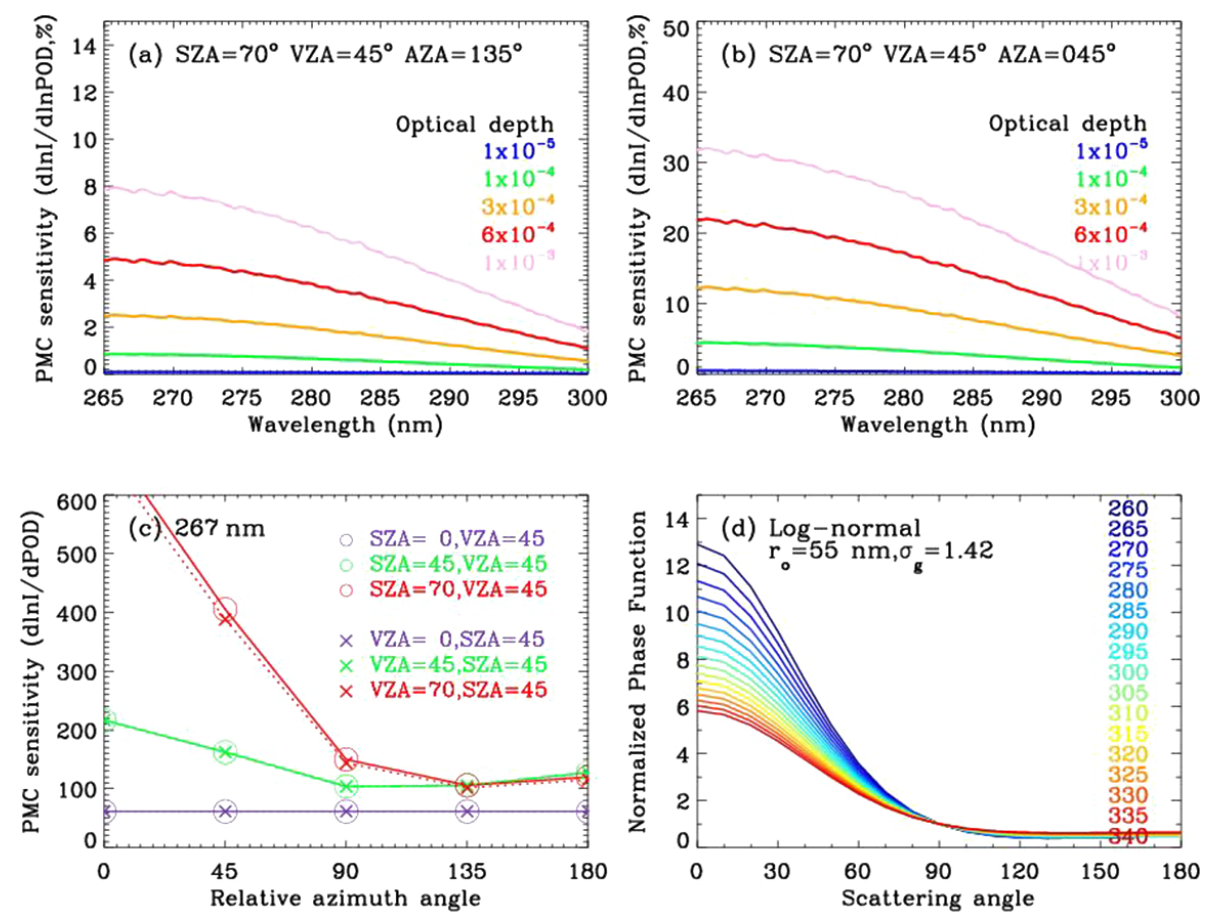

Figure 5. (a) The sensitivity of normalized radiance to five POD values ranging from $10^{-5}$ to $10^{-3}$ as functions of wavelength at $S Z A=70^{\circ}$, $\mathrm{VZA}=45^{\circ}$, and $\mathrm{AZA}=135^{\circ}$. (b) Same as (a) but for $\mathrm{AZA}=45^{\circ}$. (c) The sensitivity of normalized radiance to the unit of POD as a function of AZA with various SZAs and VZAs at $267 \mathrm{~nm}$. (d) PMC phase function as a function of scattering angle $(\Phi)$ for wavelengths ranging from 260 to $340 \mathrm{~nm}$, normalized to unity at $\Phi=90^{\circ}$.

Table 1. Correlation between OMI-convolved MLS ozone differences and PMC albedo residuals at $267 \mathrm{~nm}$ as shown in Fig. 4 but for SH 2008 summer.

\begin{tabular}{lrrr}
\hline Layer $(\mathrm{hPa})$ & Correlation & Layer $(\mathrm{hPa})$ & Correlation \\
\hline $0.15-0.22$ & -0.42 & $1.78-2.15$ & -0.48 \\
$0.32-0.46$ & -0.56 & $2.61-3.16$ & -0.35 \\
$0.68-1.00$ & -0.59 & $3.83-4.64$ & -0.26 \\
$1.21-1.47$ & -0.53 & $5.62-6.81$ & -0.14 \\
\hline
\end{tabular}

surements as the OMI measurement errors at $\sim 270 \mathrm{~nm}$ are $\sim 1 \%$.

Figure 5c shows the viewing geometry dependence of PMC sensitivity at $267 \mathrm{~nm}$. The sensitivity varies largely with SZA, VZA, and AZA, except that at AZA larger than $90^{\circ}$ the dependence on viewing geometry becomes relatively insignificant. This dependence on AZA is mainly due to the steeper phase function variation of PMCs at forwardscattering angles, displayed in Fig. 5d. The significant increase in PMC sensitivities with larger SZA or VZA at AZA $<90^{\circ}$ is mainly due to the larger photon path length for PMC scattering. Overall, the dependence on viewing geometry is a direct result of the strength of the PMC scattering.

Sensitivity studies using the optimal estimation formulation (with a loose PMC a priori constraint of $10^{-3}$ ) show that

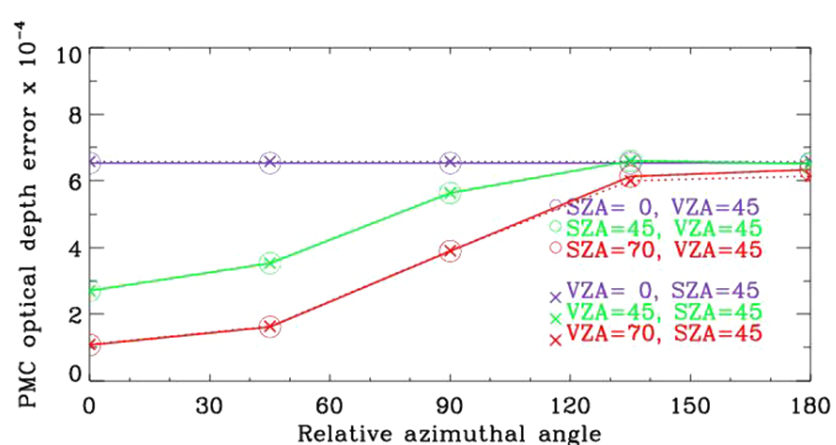

Figure 6. Same as Fig. 5c but for PMC optical depth retrieval errors (root sum square of random noise and smoothing errors).

POD can be retrieved with errors from 1 to $6.5 \times 10^{-4}$ depending on viewing geometry, as shown in Fig. 6. The POD retrieval errors are smaller at longer slant paths and smaller AZAs where the scattering is stronger and sensitivity becomes larger. As we mentioned in Sect. 2.2, the typical AZA for OMI PMC detection varies from 40 to $130^{\circ}$ (SZA $>35^{\circ}$, latitude $>55^{\circ} \mathrm{N} / \mathrm{S}$ ), and therefore the errors of OMI POD retrievals are expected to have significant dependence on the scattering angle.

Figure 7 shows the impact of PMCs on ozone profile retrievals due to the neglect of PMCs, estimated as $\frac{\partial x_{\mathrm{O}_{3}}}{\partial \boldsymbol{Y}} \cdot \frac{\partial \boldsymbol{Y}}{x_{\mathrm{POD}}}$. 
(a) $\mathrm{SZA}=70^{\circ} \mathrm{VZA}=45^{\circ} \mathrm{AZA}=135^{\circ}$

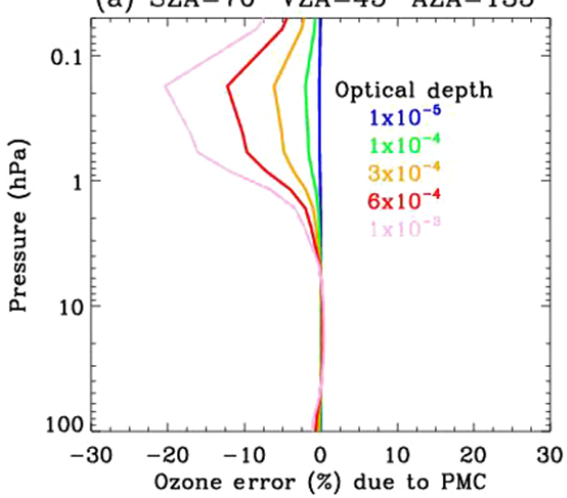

(b) $\mathrm{SZA}=70^{\circ} \mathrm{VZA}=45^{\circ} \mathrm{AZA}=045^{\circ}$

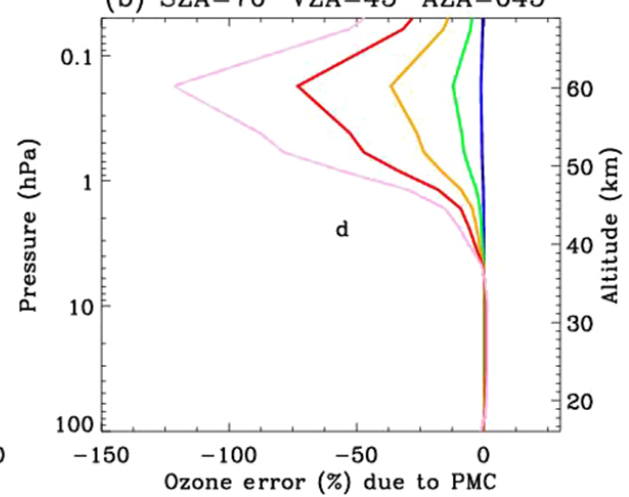

Figure 7. Ozone profile retrieval errors as functions of pressure due to the neglect of PMCs estimated by the optimal estimation approach.

$\triangle \mathrm{POD}$. This result is generally consistent with the effect of PMCs on the OMI and MLS comparisons shown in Figs. 23: the presence of PMCs results in negative ozone retrieval errors above $6 \mathrm{hPa}$; the ozone errors increase rapidly up to $\sim 0.5 \mathrm{hPa}$ and continue to increase, with the greatest peak impact at $0.2 \mathrm{hPa}(60 \mathrm{~km})$. At $\mathrm{AZA}=135^{\circ}$ (Fig. 7a) ozone errors increase $-2.5 \%$ for POD of $10^{-4}$ to $-25 \%$ for POD of $10^{-3}$. These ozone retrieval errors are expected to increase at longer slant paths and smaller AZAs. For example, as shown in Fig. $7 b$, the errors increase by a factor of 5 when the AZA is changed to $45^{\circ}$.

\subsection{Simultaneous retrievals of ozone profiles and PMC optical depth}

As mentioned in Sect. 2.3, the POD a priori value and its error are determined as 0 and $10^{-3}$, respectively, by trial and error. The POD initial value of $10^{-4}$ is close to the minimum value that is detectable from UV radiances below $300 \mathrm{~nm}$ as shown in Fig. 5a and b. An example for POD retrieved from OMI nadir measurements with three a priori errors is presented in Fig. 8. We should note that POD retrievals are performed over all pixels regardless of PMC classification. This example illustrates that the a priori error value of $10^{-4}$ is a very tight constraint as the retrieved POD values are very small for both PMC and non-PMC pixels. This also indicates that the POD can be consistently retrieved from measurement information with a priori error values $\geq 10^{-3}$, implying that the degree of freedom for signal is close to 1 for the POD parameter. The retrieved optical depths are generally larger at PMC pixels than at non-PMC pixels. Furthermore, the significant correlation $(R \cong 0.8)$ between POD and albedo residuals is demonstrated in Fig. 9a. The typical value of the retrieved optical depth is around $1-5 \times 10^{-4}$ and increases up to $15 \times 10^{-4}$ for bright PMC pixels. We select the a priori error of POD as $10^{-3}$ as it is closer to the maximum of retrieved POD values. Solution errors for PMC increase from $1 \times 10^{-4}$ at larger SZAs to $4 \times 10^{-4}$ at smaller SZAs. These retrieval errors are distinctly smaller than the a priori error of
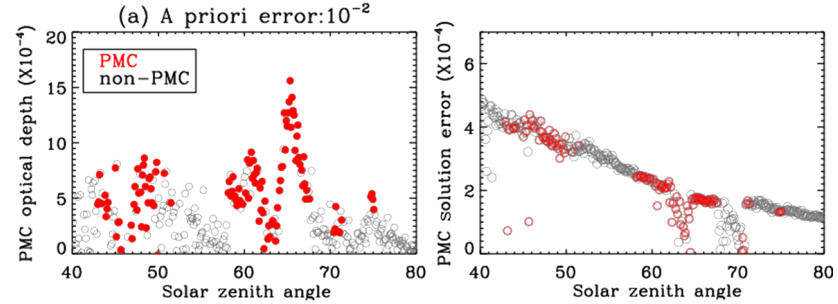

(b) A priori error: $10^{-3}$
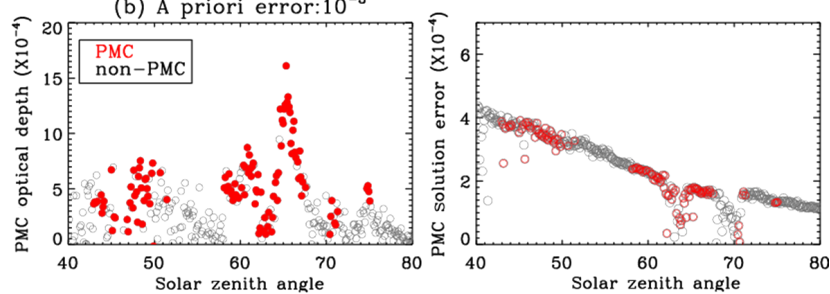

(c) A priori error: $10^{-4}$
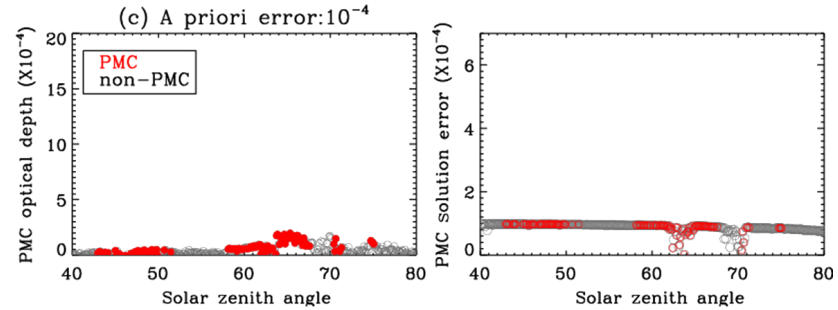

Figure 8. Retrieved PMC optical depth values and retrieval errors as functions of solar zenith angle for OMI orbit number 15881 and cross-track position 13 (UV1) on 10 July 2007 with a fixed a priori value of 0 and three a priori error values: (a) $10^{-2}$, (b) $10^{-3}$ and (c) $10^{-4}$.

$10^{-3}$. These results are consistent with the sensitivity studies as shown in Fig. 6, considering the AZAs for OMI measurements used in Fig. 8 vary from 61 and $89^{\circ}$ and VZAs are within $11^{\circ}$

Figure $9 \mathrm{~b}$ compares the retrieved ozone columns above $40 \mathrm{~km}$ including and without including the POD in the state vector. It illustrates that the retrieved ozone values tend to be larger if the PODs are simultaneously retrieved because 

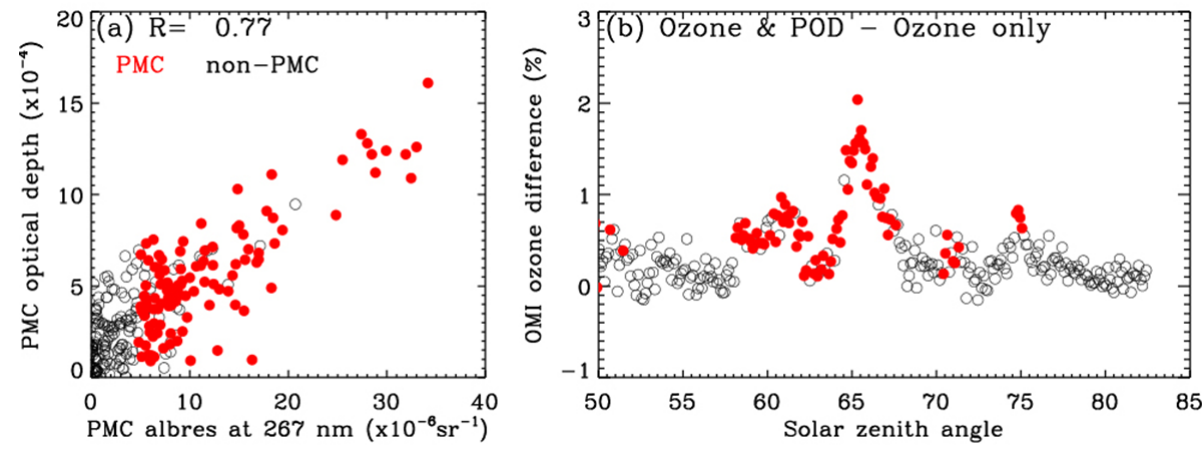

Figure 9. (a) Scatterplot between retrieved PMC optical depths and PMC albedo residuals at $267 \mathrm{~nm}$ for OMI orbit number 15881 and cross-track position 13 (UV1). (b) OMI ozone column (above $40 \mathrm{~km}$ ) differences between "ozone \& POD" and "ozone only" retrieval modes.
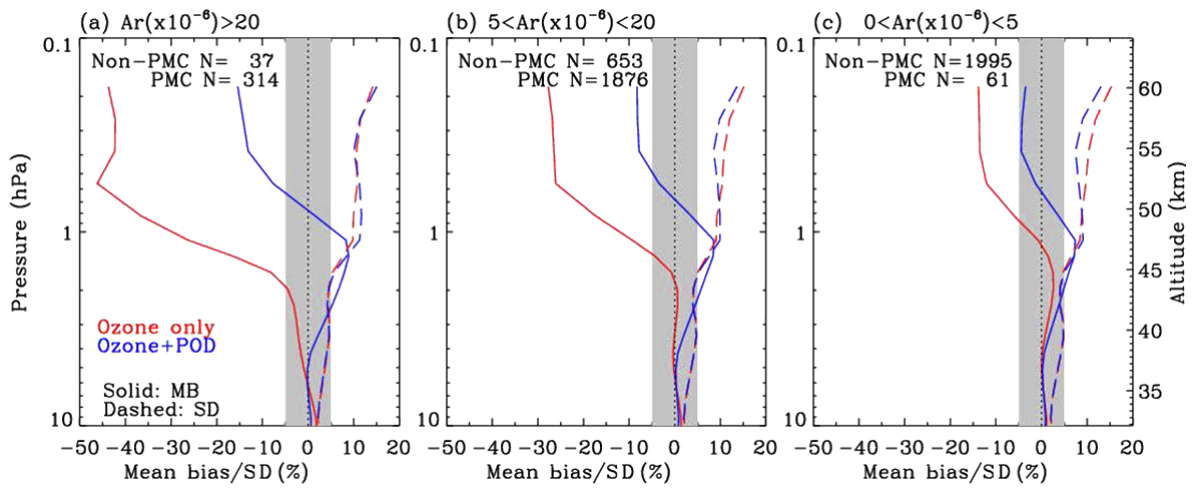

Figure 10. Collocated OMI-convolved MLS profile differences (solid lines) and their $1 \sigma$ standard deviations (dashed lines) for different ranges of PMC albedo residual (Ar) values $\left(\mathrm{sr}^{-1}\right)$ at $267 \mathrm{~nm}$ for the NH 2007 summer season. The blue and red lines represent the comparisons when OMI ozone profiles are retrieved with and without PODs, respectively. The numbers of the non-PMC and PMC pixels are included as legends.

of positive correlations between POD and ozone parameters in the upper atmosphere; the POD parameter has the most noticeable correlations ( $R=0.4-0.8)$ with ozone in the layers of $0.087-3.96 \mathrm{hPa}$ and weak correlations $(R<0.2)$ with other fitting parameters. The ozone column differences are larger for PMC pixels than for non-PMC pixels, indicating that the simultaneously retrieved POD can correct the negative biases in OMI ozone retrievals. However, there are nonPMC pixels that show significant correlation between the POD and ozone parameters at SZAs $57-67^{\circ}$, indicating that some PMC pixels are not detected from OMI. Figures 10 and 11 evaluate the improvements of OMI-MLS ozone profile comparisons with the simultaneous retrievals of POD and ozone. The systematic biases due to PMCs are mostly corrected, especially for bright PMC pixels: the negative biases range from 15 to $50 \%$ depending on the PMC albedo residuals in the upper atmosphere but are reduced from \pm 5 to $\pm 15 \%$. The significant negative correlation between OMIMLS ozone differences and PMC albedo residuals found in Fig. 4 is reduced to within 0.1 in most layers, except for the topmost two layers $(R=-0.25)$. However, the simultaneous ozone and POD retrievals systematically show positive biases ( $>8 \%$ ) for the layers of $1.21-2.15 \mathrm{hPa}$ relative to MLS data, irrespective of albedo residuals and even for non-PMC pixels, which is $\sim 5 \%$ larger than that shown in Fig. 3a for non-PMC pixels. The addition of five layers above $5 \mathrm{hPa}$ used in Fig. 10 but not in Fig. 3a causes $\sim 1 \%$ biases at $\sim 2 \mathrm{hPa}$. The remaining larger bias of $4 \%$ at $\sim 1-2 \mathrm{hPa}$ could be due to correlation between PMC and ozone, simplification of the PMC simulation, and the variability of OMI-MLS difference.

\section{Summary and discussion}

This work demonstrates the interference of tenuous PMCs on OMI ozone profile retrievals for pressures smaller than $6 \mathrm{hPa}$. The presence of PMCs leads to the systematic biases of $-2 \%$ at $2 \mathrm{hPa}$ and $-20 \%$ at $0.5 \mathrm{hPa}$ for pixels with PMCs in both hemispheres. However, the overall impact on the average ozone in the $\mathrm{NH}$ is 3 times larger than that in the $\mathrm{SH}$ if the PMC occurrence frequency is considered. The magnitude of systematic biases can increase to up to $\sim 60-80 \%$ for 

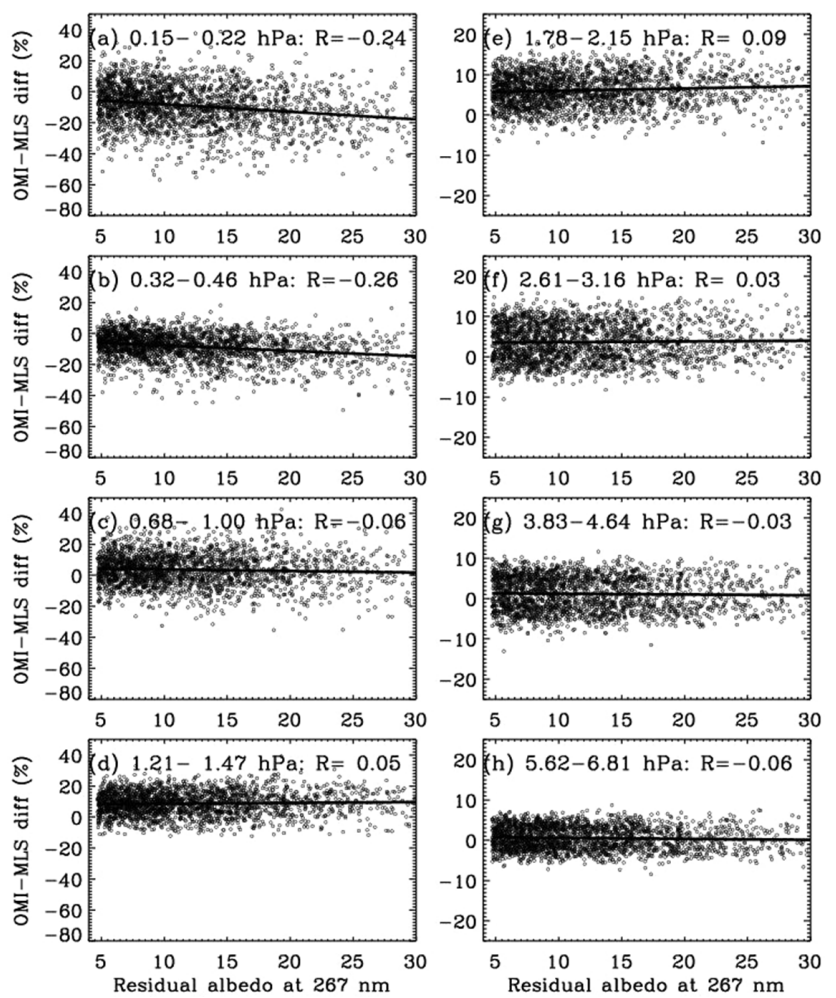

Figure 11. Same as Fig. 4 but for OMI ozone profiles simultaneously retrieved with PMC optical depths.

very bright PMC pixels. Despite the large relative biases in the upper atmosphere, the impact of PMCs on our retrieved total ozone ( $\sim 305 \mathrm{DU}$ for the $\mathrm{NH}$ summer polar region) is negligible with the absolute biases of $\sim 0.05 \mathrm{DU}$ at $0.5 \mathrm{hPa}$.

Sensitivity analysis shows that the PMC sensitivity is strongly dependent on wavelength, larger at shorter wavelengths where the signals are weak. PMC sensitivity is also strongly dependent on viewing geometry in the forwardscattering direction (e.g., relative azimuth angles less than $90^{\circ}$ ): PMC sensitivity increases with larger SZAs and VZAs due to longer path lengths for PMC scattering and especially with smaller AZAs due to much stronger forward scattering. For AZAs greater than $90^{\circ}$, the dependence becomes insignificant because the PMC scattering varies much less with viewing geometry. PMC optical depth of $\sim 10^{-4}$ is detectable from OMI data in the backscattering direction, and the PMC detection limit could be smaller for the forwardscattering direction. The maximum contribution of ignoring PMCs to ozone retrievals is found at $\sim 0.2 \mathrm{hPa}$.

To reduce PMC interference on upper-level ozone retrievals, we added the POD to the state vector in the OMI optimal estimation ozone profile algorithm. The PMC a priori value and a priori error are set at 0 and $10^{-3}$, respectively, in this study. The selected a priori error value corresponds to a loose constraint, implying that the retrieved optical depth comes mainly from measurement information. As a result, the POD can be retrieved with uncertainties of $1-4 \times 10^{-4}$ depending on solar zenith angle. A near-linear relationship is found between POD and albedo residuals $(R \sim 0.8)$. The retrieved POD values are $1-5 \times 10^{-4}$ at dark PMC pixels and increase up to $15 \times 10^{-4}$ for bright PMC pixels. We finally demonstrated that simultaneous ozone and POD retrieval improves the OMI and MLS comparisons. The negative OMI biases of $15-50 \%$ are reduced to within $\pm 15 \%$ after simultaneous ozone and POD retrievals. Moreover, this simultaneous retrieval reduces the strong negative correlation between OMI/MLS biases and PMC albedo residuals to $\sim 0.1$ above $2 \mathrm{hPa}$, which is found to be stronger than -0.5 for ozone retrieval only. However, there are some non-PMC pixels where large POD values are retrieved and hence are correlated with ozone parameters, which might represent undetected PMC pixels from OMI UV measurements. In addition, simultaneous ozone and POD retrievals cause systematic positive biases of $\sim 8 \%$ relative to MLS for the layers of $1.21-2.15 \mathrm{hPa}$, even at non-PMC pixels, which could be mostly due to correlation between PMC and ozone, simplification of the PMC simulation, and the variability of OMI-MLS differences.

This study indicates that the impact of PMC scattering is likely not negligible for stratospheric ozone retrievals from OMI, SBUV, SBUV/2, GOME, GOME-2, SCIAMACHY, and OMPS nadir profiler as the effects of PMCs have not been taken into account in any of the operational ozone profile algorithms. The presence of PMCs has greater influence on our OMI ozone retrievals compared to the PMC-induced errors on SBUV and SBUV/2 ozone retrievals shown in Thomas et al. (1991) and Bhartia et al. (2013) because OMI has more chances to see brighter PMC pixels due to its much smaller pixel size. In addition, the different ozone retrieval algorithms have different sensitivity to PMC contamination. For example, PMC-induced errors in Nimbus-7 SBUV ozone data based on the NASA Version 5 algorithm (McPeters et al., 1980) can be as large as $10 \%$. Recently, Bhartia et al. (2013) did some analysis of PMC effects on NOAA-18 SBUV/2 ozone data using the NASA Version 8.6 algorithm and found that the average effects are typically in the $2-3 \%$ range. Likewise, the OMI operational ozone profile product, OMO3PR (Kroon et al., 2011), has different response to PMC contamination due to different implementation details although it is also based on an optimal estimation with the same fitting window: the comparison between two OMI algorithms has been described in Bak et al. (2015). We compared the OMO3PR ozone product between PMC and nonPMC pixels, similarly to Fig. 2a (not shown here). The impact of PMCs on the OMO3PR product is comparable to our ozone retrievals for pressures larger than $0.1 \mathrm{hPa}$ but becomes smaller above them with erroneous ozone reduction of $\sim 10 \%$ at $0.5 \mathrm{hPa}$. This smaller impact is likely due to fitting of second-order polynomial radiance offsets to account for stray light (P. Veefkind, personal communication, 2016), which is not used in our algorithm. The impact of PMCs on total ozone retrievals such as OMTO3 (Bhartia and Welle- 
meyer, 2002) and OMDOAO3 (Veefkind et al., 2006) is negligible because the total ozone algorithms use longer wavelengths than $310 \mathrm{~nm}$ where the PMC signal is very weak and the impacts of PMCs on the ozone columns are too small to affect the total ozone retrievals.

Acknowledgements. The authors thank the OMI and MLS science teams for providing the satellite data. Research at Pusan National University by J. Bak and J. H. Kim was financially supported by "2016 Post-Doc. Development Program" of Pusan National University. Research at the Smithsonian Astrophysical Observatory by X. Liu and K. Chance, as well as J. Bak during her 3-month visit to the Harvard-Smithsonian Center for Astrophysics, was funded by the NASA Aura science team program (NNX11AE95G and NNX14AF16G) and the Smithsonian Institution.

Edited by: V. Aquila

Reviewed by: three anonymous referees

\section{References}

Bailey, S. M., Merkel, A. W., Thomas, G. E., and Carstens, J. N.: Observations of polar mesospheric clouds by the Student Nitric Oxide Explorer, J. Geophys. Res., 110, D13203, doi:10.1029/2004JD005422, 2005.

Bailey, S. M., Thomas, G. E., Rusch, D. W., Merkel, A. W., Jeppesen, C. D., Carstens, J. N., Randall, C. E., McClintock, W. E., and Russell III, J. M.: Phase functions of polar mesospheric cloud ice as observed by the CIPS instrument on the AIM satellite, J. Atmos. Sol.-Terr. Phy., 71, 373-380, doi:10.1016/j.jastp.2008.09.039, 2009.

Bak, J., Liu, X., Kim, J. H., Chance, K., and Haffner, D. P.: Validation of OMI total ozone retrievals from the SAO ozone profile algorithm and three operational algorithms with Brewer measurements, Atmos. Chem. Phys., 15, 667-683, doi:10.5194/acp-15667-2015, 2015.

Baumgarten, G. and Thomas, G. E.: The importance of ice particle shape on UV measurements of polar mesospheric clouds: SBUV/2 observations, J. Atmos. Sol.-Terr. Phy., 68, 78-84, doi:10.1016/j.jastp.2005.08.007, 2006.

Bhartia, P. K. and Wellemeyer, C. G.: TOMS-V8 total ozone algorithm, in: OMI Algorithm Theoretical Basis Document, edited by: Bhartia, P. K., NASA Goddard Space Flight Center, Greenbelt, MD, 2002.

Bhartia, P. K., McPeters, R. D., Flynn, L. E., Taylor, S., Kramarova, N. A., Frith, S., Fisher, B., and DeLand, M.: Solar Backscatter UV (SBUV) total ozone and profile algorithm, Atmos. Meas. Tech., 6, 2533-2548, doi:10.5194/amt-6-2533-2013, 2013.

Bovensmann, H., Burrows, J. P., Buchwitz, M., Frerick, J., Noel, S., Rozanov, V. V., Chance, K. V., and Goede, A. P. H.: SCIAMACHY: Mission objectives and measurement modes, J. Atmos. Sci., 56, 127-150, 1999.

DeLand, M. T. and Thomas, G. E.: Updated PMC trends derived from SBUV data, J. Geophys. Res.-Atmos., 120, 2140-2166, doi:10.1002/2014JD022253, 2015.

DeLand, M. T., Shettle, E. P., Thomas, G. E., and Olivero, J. J.: Solar backscattered ultraviolet (SBUV) observations of polar meso- spheric clouds (PMCs) over two solar cycles, J. Geophys. Res., 108, 8445, doi:10.1029/2002JD002398, 2003.

DeLand, M. T., Shettle, E. P., Thomas, G. E., and Olivero, J. J.: A quarter-century of satellite PMC observations, J. Atmos. Sol.Terr. Phy., 68, 9-29, doi:10.1016/j.jastp.2005.08.003, 2006.

DeLand, M. T., Shettle, E. P., Thomas, G. E., and Olivero, J. J.: Latitude-dependent long-term variations in polar mesospheric clouds from SBUV version 3 PMC data, J. Geophys. Res., 112, D10315, doi:10.1029/2006JD007857, 2007.

DeLand, M. T., Shettle, E. P., Levelt, P. F., and Kowalewski, M. G.: Polar Mesospheric Clouds (PMCs) Observed by the Ozone Monitoring Instrument (OMI) on Aura, J. Geophys. Res., 115, D21301, doi:10.1029/2009JD013685, 2010.

DeLand, M. T., Shettle, E. P, Thomas, G. E., and Olivero, J. J.: Direct observations of PMC local time variations by Aura OMI, J. Atmos. Sol.-Terr. Phy., 73, 2049-2064, doi:10.1016/j.jastp.2010.11.019, 2011.

Englert, C. R. and Stevens, M. H.: Polar mesospheric cloud mass and the ice budget: 1. Quantitative interpretation of mid-UV cloud brightness observations, J. Geophys. Res., 112, 08204, doi:10.1029/2006JD007533, 2007.

Eremenko, M. N., Petelina, S. V., Zasetsky, A. Y., Karlsson, B., Rinsland, C. P., Llewellyn, E. J., and Sloan, J. J.: Shape and composition of PMC particles derived from satellite remote sensing measurements, Geophys. Res. Lett., 32, L16S06, doi:10.1029/2005GL023013, 2005.

European Space Agency: The GOME Users Manual, ESA Publ. SP-1182, Publ. Div., Eur. Space Res. and Technol. Center, Noordwijk, the Netherlands, 1995.

Flynn, L., long, C., Wu, X., Evans, R., Beck, C. T., Petropavlovskikh, I., McConville, G., Yu, W., Zhang, Z., Niu, J., Beach, E., Hao, Y., Pan, C., Sen, B., Novicki, M., Zhou, S., and Seftor, C.: Performance of the Ozone Mapping and Profiler Suite (OMPS) products, J. Geophys. Res. Atmos., 119, 6181-6195, doi:10.1002/2013JD020467, 2014.

Hervig, M. E. and Stevens, M. H.: Interpreting the 35 year SBUV PMC record with SOFIE observations, J. Geophys. Res.-Atmos., 119, 12689-12705, doi:10.1002/2014JD021923, 2014.

Hervig, M., Thompson, R. E., McHugh, M., Gordley, L. L., Russell III, J. M., and Summers , M. E.: First confirmation that water ice is the primary component of polar mesospheric clouds, Geophys. Res. Lett., 28, 971-974, 2001.

Hervig, M. E., Gordley, L. L., Stevens, M. H., Russell III, J. M., Bailey, S. M., and Baumgarten, G.: Interpretation of SOFIE PMC measurements: Cloud identification and derivation Of Mass Density, Particle Shape, And Particle Size, J. Atmos. Sol.-Terr. Phy., 71, 316-330, 2009.

Kroon, M., de Haan, J. F., Veefkind, J. P., Froidevaux, L., Wang, R., Kivi, R., and Hakkarainen, J. J.: Validation of operational ozone profiles from the Ozone Monitoring Instrument, J. Geophys. Res., 116, D18305, doi:10.1029/2010JD015100, 2011.

Levelt, P. F., van den Oord, G. H. J., Dobber, M. R., Malkki, A., Visser, H., de Vries, J., Stammes, P., Lundell, J. O. V., and Saari, H.: The Ozone Monitoring Instrument, IEEE T. Geosci. Remote Sens., 44, 1093-1101, doi:10.1109/TGRS.2006.872333, 2006.

Liu, X., Bhartia, P. K., Chance, K., Spurr, R. J. D., and Kurosu, T. P.: Ozone profile retrievals from the Ozone Monitoring Instrument, Atmos. Chem. Phys., 10, 2521-2537, doi:10.5194/acp-10-25212010, 2010a. 
Liu, X., Bhartia, P. K., Chance, K., Froidevaux, L., Spurr, R. J. D., and Kurosu, T. P.: Validation of Ozone Monitoring Instrument (OMI) ozone profiles and stratospheric ozone columns with Microwave Limb Sounder (MLS) measurements, Atmos. Chem. Phys., 10, 2539-2549, doi:10.5194/acp-10-2539-2010, 2010 b.

Livesey, N. J., Read, W. G., Wagner, P. A., Froidevaux, L., Lambert, A., Manney, G. L., Millán Valle, L. F., Pumphrey, H. C., Santee, M. L., Schwartz, M. J., Wang, S., Fuller, R. A., Jamot, R. F., Knosp, B. W., and Martinez, E.: Version 4.2x Level 2 data quality and description document, JPL California Institute of Technology, Pasadena, California, 91109-8099, 2015.

Lumpe, J. D., Bailey, S. M., Carstens, J. N., Randall, C. E., Rusch, D. W., Thomas, G. E., Nielsen, K., Jeppesen, C., McClintock, W. E., Merkel, A. W., Riesberg, L., Templeman, B., Baumgarten, G., and Russell III, J. M.: Retrieval of polar mesospheric cloud properties from CIPS: Algorithm description, error analysis and cloud detection sensitivity, J. Atmos. Sol.-Terr. Phy., 104, 167196, 2013.

McPeters, R. D.: The Behavior of Ozone near the Stratopause from 2 Years of BUV Observations, J. Geophys. Res., 85, 4545-4550, 1980.

McPeters, R. D. and Labow, G. J.: Climatology 2011: an MLS and sonde derived ozone climatology for satellite retrieval algorithms, J. Geophys. Res., 1117, D10303, doi:10.1029/2011JD017006, 2012.

Munro, R., Eisinger, M., Anderson, C., Callies, J., Corpaccioli, E., Lang, R., Lefebvre, A., Livschitz, Y., and Pérez Albiñana, A.: GOME-2 on MetOp, paper presented at the 2006 EUMETSAT Meteorological Satellite Conference, Eur. Org. for the Exploit. of Meteorol. Satell., Helsinki, 2006.

Olivero, J. J. and Thomas, G. E.: Climatology of polar mesospheric clouds, J. Atmos. Sci., 43, 1263-1274, 1986.

Rapp, M., Thomas, G. E., and Baumgarten, G.: Spectral properties of mesospheric ice clouds: Evidence for nonspherical particles, J. Geophys. Res., 112, D03211, doi:10.1029/2006JD007322, 2007.

Rodgers, C. D.: Inverse Methods for Atmospheric Sounding: Theory and Practice, World Scientific Publishing, Singapore, 2000.

Schoeberl, M. R., Douglass, A. R., Hilsenrath, E., Bhartia, P. K., Beer, R., Waters, J. W., Gunson, M. R., Froidevaux, L., Gille, J. C., Barnett, J. J., Levelt, P. F., and DeCola, P.: Overview of the EOS aura mission, IEEE T. Geosci. Remote Sens., 44, 10661074, doi:10.1109/TGRS.2005.861950, 2006.

Shettle, E. P, DeLand, M. T., Thomas, G. E., and Olivero, J. J.: Long term variations in the frequency of polar mesospheric clouds in the Northern Hemisphere from SBUV, Geophys. Res. Lett., 36, L02803, doi:10.1029/2008GL036048, 2009.

Spurr, R. J. D.: VLIDORT: A linearized pseudo-spherical vector discrete ordinate radiative transfer code for forward model and retrieval studies in multilayer multiple scattering media, J. Quant. Spectrosc. Ra., 102, 316-342, 2006.
Spurr, R. J. D.: Linearized pseudo-spherical scalar and vector discrete ordinate radiative transfer models for use in remote sensing retrieval problems, in: Light Scattering Reviews, edited by: Kokhanovsky, A., Springer, New York, 2008.

Taylor, M. J., Gadsden, M., Lowe, R. P., Zalcik, M. S., and Brausch, J.: Mesospheric cloud observations at unusually low latitudes, J. Atmos. Sol.-Terr. Phy., 64, 991-999, 2002.

Thomas, G. E.: Solar mesosphere explorer measurements of polar mesospheric clouds (noctilucent clouds), J. Atmos. Terr. Phys., 46, 819-824, doi:10.1016/0021-9169(84)90062-X, 1984.

Thomas, G. E., McPeters, R. D., and Jensen, E. J.: Satellite observations of polar mesospheric clouds by the solar backscattered ultraviolet spectral radiometer - Evidence of a solar cycle dependence, J. Geophys. Res., 96, 927-939, 1991.

von Savigny, C. and Burrows, J. P.: Latitude variation of NLC particle radii derived from northern hemisphere SCIAMACHY/Envisat limb measurements, Adv. Space Res., 40, 765771, 2007.

von Savigny, C., Kokhanovsky, A., Bovensmann, H., Eichmann, K.U., Kaiser, J., Noel, S., Rozanov, A. V., Skupin, J., and Burrows, J. P.: NLC detection and particle size determination: first results from SCIAMACHY on Envisat, Adv. Space Res., 34, 851-856, 2004.

Veefkind, J. P., De Haan, J. F., Brinksma, E. J., Kroon, M., and Levelt, P. F.: Total ozone from the ozone monitoring instrument (OMI) using the DOAS technique, IEEE T. Geosci. Remote Sens., 44, 1239-1244, doi:10.1109/TGRS.2006.871204, 2006.

Warren, S. G.: Optical constants of ice from the ultraviolet to the microwave, Appl. Opt., 23, 1206-1225, doi:10.1364/AO.23.001206, 1984

Waters, J. W., Froidevaux, L., Harwood, R. S., Jarnot, R. F., Pickett, H. M., Read, W. G., Siegel, P. H., Cofield, R. E., Filipiak, M. J., Flower, D. A., Holden, J. R., Lau, G. K., Livesey, N. J., Manney, G. L., Pumphrey, H. C., Santee, M. L., Wu, D. L., Cuddy, D. T., Lay, R. R., Loo, M. S., Perun, V. S., Schwartz, M. J., Stek, P. C., Thurstans, R. P., Boyles, M. A., Chandra, K. M., Chavez, M. C., Chen, G.-S., Chudasama, B. V., Dodge, R., Fuller, R. A., Girard, M. A., Jiang, J. H., Jiang, Y., Knosp, B. W., LaBelle, R. C., Lam, J. C., Lee, K. A., Miller, D., Oswald, J. E., Patel, N. C., Pukala, D. M., Quintero, O., Scaff, D. M., Van Snyder, W., Tope, M. C., Wagner, P. A., and Walch, M. J.: The Earth observing system microwave limb sounder (EOS MLS) on the aura Satellite, IEEE T. Geosci. Remote Sens., 44, 1075-1092, doi:10.1109/TGRS.2006.873771, 2006. 